\title{
Esporotricose canina: relato de caso
}

\author{
[Canine sporotrichosis: case report] \\ N.T. Souza $^{1 *}$, A.C.B.M. Nascimento ${ }^{2}$, J.O.T. Souza ${ }^{3}$, F.C.G.C.A. Santos ${ }^{4}$, R.B. Castro ${ }^{5}$ \\ ${ }^{1}$ Aluna de graduação - Faculdade de Medicina Veterinária - FAA - Valença, RJ \\ ${ }^{2}$ Aluna de graduação - Faculdade de Medicina Veterinária - UNIPAC - Juiz de Fora, MG \\ ${ }^{3}$ Faculdade de Medicina Veterinária - UNIPAC- Juiz de Fora, MG \\ ${ }^{4}$ Faculdade de Medicina Veterinária de Valença - FAA - Valença, RJ \\ ${ }^{5}$ Médico veterinário autônomo
}

\begin{abstract}
RESUMO
Relata-se um caso de esporotricose em um cão da raça Boxer, macho, com seis anos, encaminhado para uma consulta por causa de massa na região nasal e de dispneia. Após o exame físico, o animal foi internado para a realização de citologia, histologia e radiografia. Nos exames citológico e radiográfico, não foram constatadas alterações que justificassem a massa e a dispneia. Na histologia, observou-se a presença de um granuloma contendo dois esporos de Sporothrix schenckii. Foi realizado tratamento com itraconazol 5mg/kg BID por 60 dias. Após esse período, a massa desapareceu e a respiração do animal melhorou, tendo sido recomendada a manutenção da terapia por mais 30 dias, para evitar recidiva.
\end{abstract}

Palavras-chave: cão, zoonose, dermatofitose, Sporothrix schenckii

\begin{abstract}
A case of canine sporotrichosis was reported in a six-year-old male Boxer, referred to a veterinary hospital because of a mass in the region of the nose and dyspnea. After physical examination, the animal was submitted to cytological, histological, and radiographic exams. The cytological and radiographic exams showed no alterations that could justify the mass and the dyspnea. The histological exam showed the presence of a granuloma with two Sporothrix schenckii spores. The dog was treated with itraconazol $5 \mathrm{mg} / \mathrm{kg}$ BID during 60 days. After this period, the mass disappeared and breathing improved. The therapy was maintained for 30 other days to avoid relapse.
\end{abstract}

Keywords: dog, zoonosis, dermatophytosis, Sporothrix schenckii

\section{INTRODUÇ̃̃O}

Sporothrix schenckii é um fungo dimórfico presente no solo em associação com restos vegetais em regiões de clima temperado e tropical úmido. É um fungo saprófita ambiental e cosmopolita que existe na forma de bolor em temperaturas ambientes de 25 a $30^{\circ} \mathrm{C}$, e, como levedura, em temperatura corpórea de $37^{\circ} \mathrm{C}$. A levedura tem um formato característico de charuto ou cigarrete que mede de 2 por $3 \mu$ a 3 por $10 \mathrm{~mm}$ (Bezerra et al., 2006).

A esporotricose pode acometer diversas espécies de animais e já foi descrita em equinos, cães, felinos, bovinos, suínos, camelos, primatas e no homem. A transmissão da doença é resultante da inoculação direta do agente por fômites (Hirano et al., 2006; Tânia et al., 2006).

No cão, a esporotricose é tida como incomum a rara, sendo mais comuns as dermatofitoses causadas por Microsporum canis, M. gypseum e Trichophyton mentagrophytes (Paixão et al., 2001; Morielo, 2004). A forma de apresentação mais comum nessa espécie é a cutânea, em que são observados nódulos firmes múltiplos, áreas alopécicas e lesões ulceradas não dolorosas nem pruriginosas, principalmente no tronco, cabeça e orelhas. Os nódulos podem ulcerar ou desenvolver trajetos drenantes. Existe também a forma cutaneolinfática, com um nódulo na face distal de um membro e infecção ascendente via linfática, e a

Recebido em 2 de julho de 2008

Aceito em 16 de abril de 2009

Email: nati_tavares@yahoo.com.br 
forma disseminada, que é extremamente rara (Muller e Kirk, 1996; Whittemore e Webb, 2007). Uma vez que os elementos fúngicos encontrados em tecidos infectados, fezes e exsudatos de gatos são mais numerosos que os encontrados em cães, a transmissão para o homem é mais comum a partir de gatos (Marques et al., 1993).

O diagnóstico é realizado por meio de citologia por esfregaço direto, impressão, suabe ou raspado cutâneo. Os métodos de coloração de escolha são o Wright modificado ${ }^{1}$ e o do azul de metileno. Podem-se indicar também cultura fúngica e biópsia (Muller e Kirk, 1996).

O tratamento de escolha em cães, gatos e humanos é o realizado com iodeto de sódio e potássio, na dose de $44 \mathrm{mg} / \mathrm{kg}$ a cada oito ou 12 horas, devendo-se atentar para o iodismo, mais comum de ocorrer em felinos. Nesse caso, o animal apresenta sinais de febre, anorexia, ptialismo, ressecamento da pele, hiperexcitabilidade, vômito ou diarreia (Nobre et al., 2002).

Podem-se utilizar, também, os fármacos imidazóis e os triazóis até a cicatrização das lesões e até que as culturas se tornem negativas. O uso do medicamento pode estender-se por até 30 dias após a cura clínica (Nobre et al., 2002; Wiebe e Karriker, 2005; Nunes e Escosteguy, 2005). Dentre os triazóis, o itraconazol, derivado triazólico sintético, apresenta largo espectro de ação contra micoses sistêmicas e superficiais, devendo ser sempre ministrado após as refeições. Os efeitos colaterais do uso desse fármaco são anorexia, náusea e aumento da fosfatase alcalina e da aminotransferase. Quando comparado ao cetoconazol, o itraconazol tem maior espectro de ação, é mais efetivo em doses menores e apresenta menos efeitos colaterais. A dose preconizada no caso da esporotricose é de 5 a $10 \mathrm{mg} / \mathrm{kg}$ a cada $12-24$ horas, tanto para cães quanto para gatos (Nobre et al., 2002; Wiebe e Karriker, 2005).

O cetoconazol é um antifúngico do grupo dos imidazóis. Tem amplo espectro de ação contra micoses sistêmicas e superficiais e é usado, na dose de 5 a $10 \mathrm{mg} / \mathrm{kg}$ SID, para cães e gatos. Nas micoses profundas, recomenda-se sua associação

${ }^{1}$ Diff Quik, Dade Behring Lab. - Nohbrook - EUA. com anfotericina $\mathrm{B}$, esta utilizada na dose de 0,1 a $0,6 \mathrm{mg} / \mathrm{kg}$ por via endovenosa, em dias alternados. $\mathrm{O}$ cetoconazol tem latência relativamente demorada, o que pode comprometer a vida do paciente. Os efeitos colaterais descritos em cães são: inapetência, anorexia, náusea (muito comum), vômito e diarreia. Observa-se, também, elevação de enzimas hepáticas. $\mathrm{O}$ prognóstico para a esporotricose varia de regular a bom, porém pode ocorrer recidiva, principalmente devido ao uso incorreto dos medicamentos (Nobre et al., 2002; Wiebe e Karriker, 2005).

O objetivo deste trabalho é relatar um caso clínico de esporotricose em um cão em razão de sua importância epidemiológica e por se tratar de uma doença incomum nessa espécie.

\section{CASUÍSTICA}

Um cão macho da raça Boxer, com seis anos de idade, pesando $35 \mathrm{~kg}$, foi levado para consulta devido a problemas com massa na fossa nasal e dificuldade respiratória.

Conforme o relato do proprietário, o animal estava sendo tratado, há cinco semanas, para rinite alérgica com prednisolona ${ }^{2}$, na dose de $0,5 \mathrm{mg} / \mathrm{kg}$ BID. Diminuição do apetite e perda de peso também foram observadas. $\mathrm{O}$ animal convivia com outro cão em uma grande área, porém não foram observadas alterações no outro animal. No exame físico, constatou-se massa na fossa nasal bem delimitada, não-ulcerada, medindo aproximadamente $0,5 \mathrm{~cm}$ de diâmetro, além de dispneia na fase inspiratória (Fig. 1).

O animal foi internado para a realização de exames complementares, como citologia, histologia e radiografia, e para ser submetido à antibioticoterapia. A corticoideterapia sistêmica foi mantida até a obtenção dos resultados dos exames solicitados. Após a internação, procedeuse à coleta do material para citologia por meio de suabe estéril e fixação em álcool 70. Realizada a biópsia por meio de um punch, a amostra foi acondicionada em formalina $10 \%$ e encaminhada para o laboratório para a realização do exame histológico. Neste, a amostra foi corada pelo ácido periódico de Schiff, conforme Marques et al. (1993). A cicatrização da ferida cirúrgica ocorreu por segunda intenção.

\footnotetext{
${ }^{2}$ Dermacorten $^{\circledR}$ - Ouro Fino - Ribeirão Preto, Brasil.
} 
O cultivo de secreção da fossa nasal, para o exame citológico, não demonstrou elementos fúngicos ou bacterianos. No exame radiográfico do tórax, não foram observadas alterações significativas e, no exame histológico, observouse piogranuloma, caracterizado por acúmulo nodular de histiócitos com polimorfonucleares de permeio e halo de pequenos mononucleares. $\mathrm{Na}$ lâmina, observaram-se dois esporos diminutos na porção central do granuloma, confirmando o diagnóstico de esporotricose (Fig. 2).

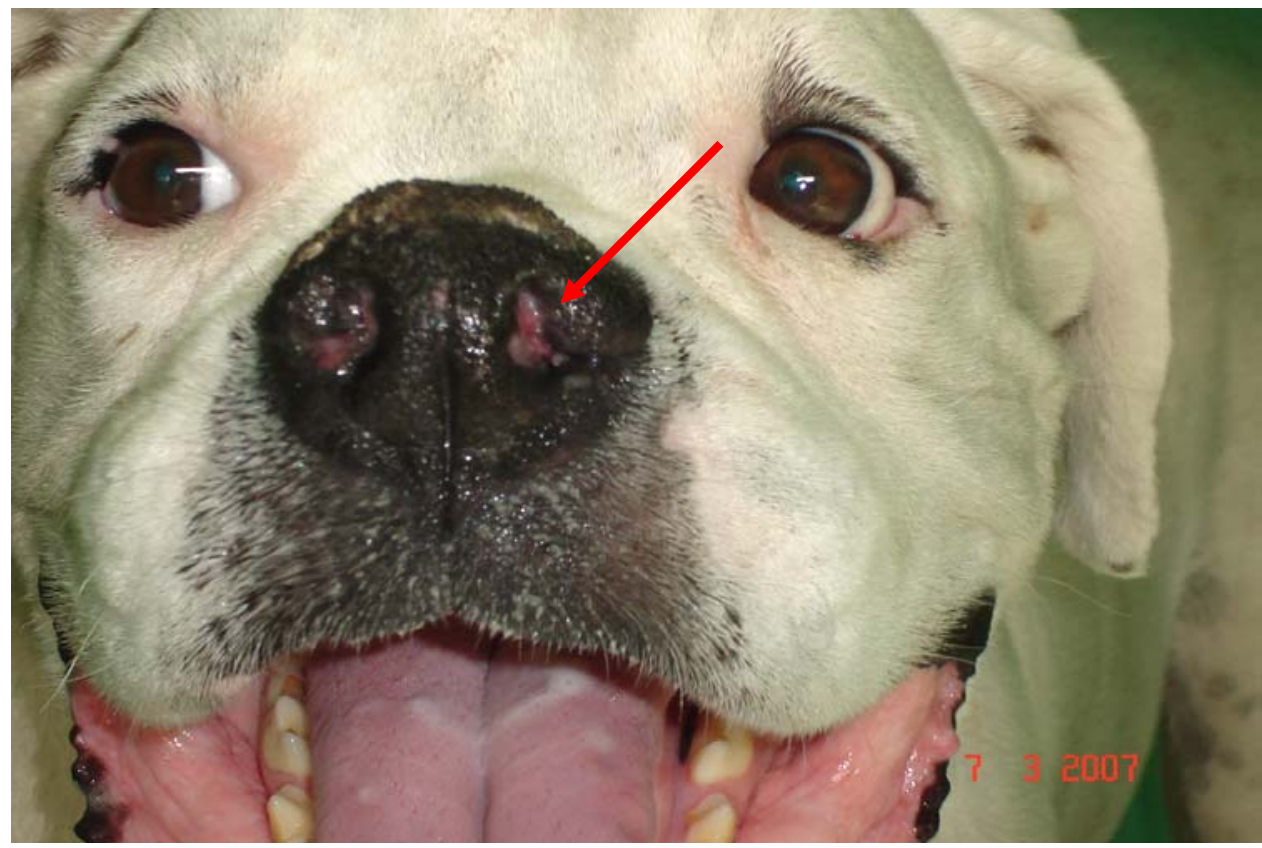

Figura 1. Cão da raça Boxer com seis anos, macho, apresentando massa na fossa nasal esquerda bem delimitada, sem ulcerações, medindo aproximadamente $0,5 \mathrm{~cm}$ de diâmetro.

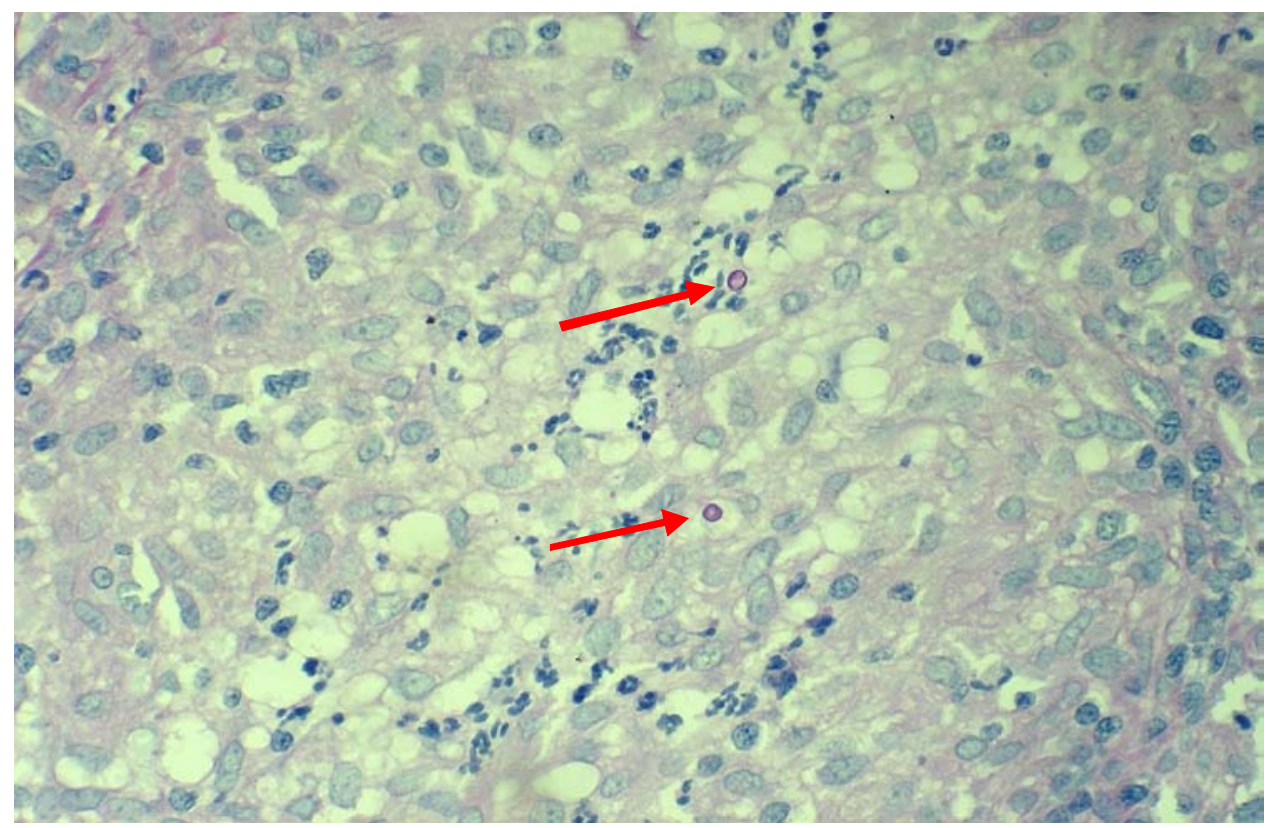

Figura 2. Porção central do granuloma com dois esporos diminutos corados pelo PAS (reação do ácido periódico de Schiff) observado no cão Boxer, macho de seis anos. 
Como o animal estava sendo tratado com corticoide há aproximadamente cinco semanas, seu uso foi diminuído progressivamente, e foi iniciado o uso de itraconazol por via oral na dose de $5 \mathrm{mg} / \mathrm{kg}$ BID por 60 dias, sempre após as refeições. Após esse período, desapareceram os sinais clínicos da enfermidade, e recomendou-se a administração do fármaco por mais 30 dias após a cura clínica, a fim de evitar a recidiva.

\section{DISCUSSÃO}

Nos relatos de esporotricose em cães, os sinais clínicos comumente identificados são: massas alopécicas, ulceradas, não-pruriginosas na região torácica dorsal (Koehne et al., 1971), na cabeça, na orelha (Scott et al., 1973; Shany, 2000) e no plano nasal (Shany, 2000; Whittemore e Webb, 2007).

No exame radiográfico, porém, não se observaram alterações significativas, como as encontradas por Scott et al. (1973) e Shany (2000). Whittemore e Webb (2007) observaram, por meio de exame citológico, a presença de um processo inflamatório linfocítico; neste relato, entretanto, não foram constatadas alterações inflamatórias. No presente caso, não foi utilizada a cultura fúngica, que auxilia no diagnóstico (Koehne et al., 1971; Scott et al., 1973), principalmente quando o diagnóstico histopatológico fornece resultado falso-negativo, ou seja, quando não é observada a presença de esporos na amostra.

De acordo com Muller e Kirk (1996), no tratamento da esporotricose, são utilizados antifúngicos, principalmente $\mathrm{o}$ iodeto de potássio, apesar de suas contraindicações. Recomenda-se utilizá-los por longos períodos e, após a cura clínica, o tratamento deve se estender por mais 30 dias a fim de se evitar a recidiva.

O medicamento de escolha neste caso foi o itraconazol. Durante sua administração, não foram relatados efeitos colaterais, o que confirma a segurança e a baixa toxidade dos triazólicos. A biodisponibilidade do itraconazol é máxima quando a ingestão se faz imediatamente após uma refeição, sendo sua eliminação bifásica, com meia-vida terminal em um dia (Nobre et al., 2002; Hector, 2005). A eficácia do tratamento com itraconazol demonstrada neste caso também foi encontrada por Hirano et al. (2006) na esporotricose felina.
Como mencionado anteriormente, o animal estava sendo tratado com prednisolona, o tratamento foi suspenso devido ao seu efeito imunossupressor. Os glicocorticoides devem ser evitados tanto durante como após o tratamento, já que drogas imunossupressoras foram descritas como causas de recidiva de esporotricose clínica, mesmo depois de seis meses da cura clínica (Muller e Kirk, 1996; Whittemore e Webb, 2007).

Apesar de o cão não desempenhar papel relevante na epidemiologia da esporotricose e de não eliminar número elevado de esporos em exsudatos, razão pela qual apresenta menor potencial zoonótico, o proprietário foi informado dos riscos de infecção e orientado sobre os cuidados a serem tomados diante do caso. Até o término do tratamento, não haviam sido evidenciados sinais clínicos da doença no outro cão que convivia com o animal e nem no proprietário, diferenciando-se este caso daqueles de esporotricose com transmissão a humanos, por intermédio de felinos, relatados por Marques et al. (1993).

\section{CONCLUSÃO}

Confirma-se a importância da histologia no diagnóstico de esporotricose e o sucesso terapêutico do uso de itraconazol no tratamento desta patologia.

\section{REFERÊNCIAS BIBLIOGRÁFICAS}

BEZERRA, L.M.L.; SCHUBABCH, A.; COSTA, R.O. Sporothrix schenckii and Sporotrichosis. An. Acad. Bras. Cienc., v.78, p.293-308, 2006.

HECTOR, R.F. An overview of antifungal drugs and their use for treatment of deep and superficial mycoses in animals. Clin. Tech. Small Anim. Pract., v.20, p.240-249, 2005.

HIRANO, M.; WATANABE, K.; MURAKAMI, M. et al. A case of feline sporotrichosis. J. Vet. Med. Sci., v.68, p.283-284, 2006.

KOEHNE, G.; POWELL, H.S.; HAIL, R.I. Sporotrichosis in a dog. J. Am. Vet. Med. Assoc., v.159, p.892-894, 1971.

MARQUES, S.A.; FRANCO, S.R.V.S.; CAMARGO, R.M.P.de. et al. Esporotricose do gato doméstico (Felis catus): transmissão 
humana. Rev. Inst. Med. Trop. São Paulo, v.35, p.327-330, 1993.

MORIELO, K.A. Treatment of dermatophytosis in dogs and cats: review of publish studies. Vet. Dermatol., v.15, p.99-107, 2004.

MULLER, G.H.; KIRK, R.W. (Eds). Dermatologia de pequenos animais. Rio de Janeiro: Interlivros, 1996. p.88-103.

NOBRE, M.O.; NASCENTE, P.S.; MEIRELES, M.C. et al. Drogas antifúngicas para pequenos e grandes animais. Cienc. Rural, v.32, p.175-184, 2002.

NUNES, F.C.; ESCOSTEGUY, C.C. Esporotricose humana associada à transmissão por gato doméstico: relato de caso e revisão de literatura. Rev. Clin. Vet., v.54, p.66-68, 2005.

PAIXÃO, G.C.; SIDRIM, J.J.C.; CAMPOS, G.M.M. et al. Dermatophytes and saprobe fungi isolated from dogs and cats in the city of Fortaleza, Brazil. Arq. Bras. Med. Vet. Zootec., v.53, p.568-573, 2001.
SCOTT, D.W.; BENTINCK-SMITH, J.; HAGGERT, G.F. Sporotrichosis in three dogs. Cornell Vet., v.64, p.416-426, 1973.

SHANY, M. A mixed fungal infection in a dog: sporotrichosis and cryptococcosis. Can. Vet. J., v.41, p.799-800, 2000.

TÂNIA, M.P.; SCHUBACH, T.M.P.; SCHUBACH, A. et al. Canine sporotrichosis in Rio de Janeiro, Brazil: clinical presentation, laboratory diagnosis and therapeutic response in 44 cases (1998-2003). Med. Mycol., v.44, p.8792, 2006.

WHITTEMORE, J.C.; WEBB, C.B. Successful treatment of nasal sporotrichosis in a dog. Can. Vet. J., v.48, p.411-414, 2007.

WIEBE, V.; KARRIKER, M. Therapy of systemic fungal infections: A pharmacologic perspective. Clin. Tech. Small Anim. Pract., v.20, p.250-257, 2005. 